\title{
RESPOSTA DO HÍBRIDO DE SORGO-SUDÃO À ADUBAČ̃̃O NITROGENADA E POTÁSSICA: COMPOSIÇÃO QUÍMICA E DIGESTIBILIDADE IN VITRO DA MATÉRIA ORGÂNICA ${ }^{1}$
}

\author{
Nitrogen and potassium fertilization effects on a sorghum hybrid: chemical composition and in vitro \\ digestibility of organic matter
}

\author{
Flávia Fernanda Simili², Ricardo Andrade Reis ${ }^{3}$, Bruna Nucci Furlan ${ }^{4}$, \\ Cláudia Cristina Paro de Paz $^{2}$, Maria Lúcia Pereira Lima², Paulo Affonso Bellingieri
}

\begin{abstract}
RESUMO
A pesquisa foi instalada no Setor de Forragicultura da FCAV/UNESP-Jaboticabal, objetivando avaliar a composição química e a digestibilidade in vitro da matéria orgânica (DIVMO) do híbrido de Sorgo-sudão cv. AG 2501C, no outono e inverno. O manejo da pastagem foi conduzido simulando o sistema de lotação intermitente. O experimento foi desenvolvido de março a setembro de 2002. A forrageira foi submetida a nove tratamentos: três níveis de nitrogênio $(100,200$ e $300 \mathrm{~kg}$ de N/ha) e três níveis de potássio $(0,80$ e $160 \mathrm{~kg}$ de $\mathrm{K}_{2} \mathrm{O} / \mathrm{ha}$ ), em delineamento experimental em blocos casualizados e parcelas subdivididas. A adubação nitrogenada e potássica não foram significativas para a DIVMO. O nitrogênio influenciou a proteína bruta (PB) com valores de 15,1; 16,4 e 15,7 \%, a fibra em detergente neutro (FDN) com valores de 65,3; 65,8 e 64,5\% e fibra em detergente ácido (FDA) com 35,5; 37,8 e 39,6\% para 100; 200 e $300 \mathrm{~kg} \mathrm{~N} / \mathrm{ha}$. O potássio aumentou significativamente a lignina das plantas. O melhor nível obtido foi $100 \mathrm{~kg} / \mathrm{ha}$ de nitrogênio, sem potássio.
\end{abstract}

Termos para indexação: Gramíneas anuais de verão, proteína bruta, Sorghum bicolor x Sorghum sudanense.

\begin{abstract}
The research was carried out in the Forage Section of FCAV/UNESP-Jaboticabal, to evaluate the chemical composition and the in vitro digestibility of organic matter (IVDOM) of the hybrid sorghum cv. AG 2501C (Sorghum bicolor $x$ Sorghum sudanense) during autumn/winter. The management of pasture was conducted by a simulation of a rotational stocking. The experiment was developed from March to September 2002. The forage was submitted to nine treatments: three nitrogen levels $(100,220$ and $300 \mathrm{~kg} /$ ha) and three potassium levels $(0,80$ and $160 \mathrm{~kg} / \mathrm{ha}$ ) in a randomized blocks design and split plot. No effect of nitrogen and potassium fertilization on IVDOM was found. Nitrogen had influence on crude protein with values of $15.1,16.4$ and $15.7 \%$ of CP and $65.3,65.8$ and $64.5 \%$ of neutral detergent fiber (NDF) and 35.5, 37.8, 39.6\% of acid detergent fiber (ADF), for 100, 200 and $300 \mathrm{~kg} N / \mathrm{ha}$. The potassium fertilization increased the lignin of plant. We concluded that, the best level was $100 \mathrm{~kg} / \mathrm{ha}$ of nitrogen fertilization, without potassium.
\end{abstract}

Index terms: Crude protein, Sorghum bicolor x Sorghum sudanense, tropical annual grass.

(Recebido em 20 de novembro de 2006 e aprovado em 16 de julho de 2007)

\section{INTRODUÇÃO}

Nas regiões tropicais e subtropicais, culturas como milheto (Pennisetum americanum (L.) Leeke) e híbrido de Sorgo-sudão (Sorghum bicolor (L.) Moench $x$ Sorghum sudanense (Piper) Stapf) vêm se destacando por apresentarem maior flexibilidade de épocas de plantio, alto potencial produtivo, podendo constituir alternativas de forragem para intensificar a produção animal, principalmente em épocas de escassez de alimento.
Entre os macronutrientes, o nitrogênio e o potássio possuem papel fundamental para a nutrição das plantas; o nitrogênio, por ser constituinte essencial das proteínas e interferir diretamente no processo fotossintético, pela sua participação na molécula de clorofila, e o potássio, por ser o cátion em maior concentração nas plantas, sendo um nutriente com relevantes funções fisiológicas e metabólicas como ativação de enzimas, fotossíntese, translocação de assimilados e, também absorção de nitrogênio e síntese protéica, tornando-se, portanto, limitante em sistema de utilização intensiva de solo.

\footnotetext{
${ }^{1}$ Parte da dissertação de mestrado defendido na Faculdade de Ciências Agrárias e Veterinárias - UNESP - Jaboticabal.

${ }^{2}$ Doutores - Pólo Centro-Leste - Agência Paulista de Tecnologia dos Agronegócios/APTA - Avenida Bandeirantes, 2419 - Vila Virgínia - $14030-670$ Ribeirão Preto, SP - flaviasimili@apta.sp.gov.br; ccppaz@apta.sp.gov.br; marialucia@apta.sp.gov.br

${ }^{3}$ Doutor - Departamento de Zootecnia - Faculdade de Ciências Agrárias e Veterinárias/FCAV - Universidade Estadual Paulista/UNESP - Via de Acesso Professor Paulo Donato Castellane, Km 5 - 14870-120 - Jaboticabal, SP - rareis@fcav.unesp.br

${ }^{4}$ Zootecnista - Rua Floriano Peixoto, 1100 - Centro - 14870-120 - Jaboticabal, SP - brunazoo@yahoo.com.br

${ }^{5}$ Doutor - Faculdade de Ciências Agrárias e Veterinárias/FCAV - Universidade Estadual Paulista/UNESP - Via de Acesso Professor Paulo Donato

Castellane, Km 5 - 14870-120 - Jaboticabal, SP - pabellin@fcav.unesp.br
} 
O efeito positivo da adubação nitrogenada sobre o rendimento e qualidade da forragem de sorgo é unanimemente relatado por diversos pesquisadores, assim Broyles \& Fribourg (1959), Hart \& Burton (1965) e Jung et al. (1964) relatam aumentos na produção e qualidade da forragem de sorgos até $280 \mathrm{~kg}$ de N/ha.

Medeiros et al. (1979) estudando o rendimento e a qualidade da cultivar sorgo sordan (Sorghum bicolor $x$ Sorghum sudanense) submetido a diferentes níveis de adubação nitrogenada observaram variações na massa seca de 9,1 a 16,5 t/ha e no teor de PB de 10 a 14\%, em resposta às doses de $\mathrm{N}(0 ; 100 ; 200$ e $300 \mathrm{~kg} \mathrm{~N} / \mathrm{ha})$.

Ferreira et al. (2000) avaliando a produtividade e composição química do Sorgo-sudão e seus híbridos, entre eles a cv. AG 2501C, com plantio realizado em fevereiro, em Sete Lagoas-MG, colhidos com 42 e 56 dias após o plantio, observaram que a massa de forragem do híbrido de Sorgosudão cv. AG 2501C foi de 3,04 e 5,83 t/ha; a PB variou de 10,7 a $8,4 \%$; a FDN foi de 70,0 e 71,08\%; a FDA foi de 40,19 e $39,81 \%$ para 42 e 56 , dias respectivamente.

A composição mineral de espécies forrageiras varia com uma série de fatores, entre os quais se destacam: solo e adubações realizadas, diferenças genéticas entre espécies, variedades, estações do ano e intervalo de cortes.

Objetivou-se, neste trabalho avaliar a composição química e a digestibilidade in vitro da matéria orgânica do híbrido de Sorgo-sudão cv. AG 2501C, submetido à adubação nitrogenada e potássica no período outonoinverno, sob lotação rotacionada.

\section{MATERIAL E MÉTODOS}

O experimento foi conduzido no Setor de Forragicultura da Faculdade de Ciências Agrárias e Veterinárias de Jaboticabal - UNESP, situado a $21^{\circ} 15^{\prime}$ de latitude (S), 48 $18^{\prime}$ de longitude (W) e altitude média de 595 metros. O solo foi classificado como Latossolo vermelho distrófico, textura média (EMBRAPA, 1999). A análise de solo revelou média de 5,7 para $\mathrm{pH}$, matéria orgânica de $23 \mathrm{~g} / \mathrm{dm}^{3}$, fósforo em resina de $33 \mathrm{mg} / \mathrm{dm}^{3}$, potássio de $4,2 \mathrm{mmol} / \mathrm{dm}^{3}$, cálcio de $41 \mathrm{mmol} / \mathrm{dm}^{3}$, magnésio com $18 \mathrm{mmol} / \mathrm{dm}^{3}$, hidrogênio mais alumínio com $20 \mathrm{mmol} /$ $\mathrm{dm}^{3}$, capacidade de troca de cátions de $83 \%$, soma de bases de $63,3 \%$ e saturação por bases (V\%) de $76 \%$. Os dados metereológicos foram obtidos na Estação Agrometereológica do Departamento de Ciências Exatas, UNESP, Jaboticabal (Figura 1).

A semeadura foi realizada em linhas de plantio, em 11 de março de 2002, com espaçamento de $22,5 \mathrm{~cm}$, usandose de $16 \mathrm{~kg} / \mathrm{ha}$ de sementes de híbrido de Sorgo-sudão cv. AG 2501C. Na adubação de plantio foi utilizado $100 \mathrm{~kg} / \mathrm{ha}$ de $\mathrm{P}_{2} \mathrm{O}_{5}$ na forma de superfosfato simples. As adubações referentes aos tratamentos experimentais foram realizadas por cobertura, 20 dias após o plantio ou após os ciclos de pastejo. A área experimental foi de $4.374 \mathrm{~m}^{2}$, onde cada parcela de $162 \mathrm{~m}^{2}$ representava um tratamento, totalizando 27 parcelas experimentais.

A pastagem foi manejada simulando o sistema de lotação intermitente, com três dias de ocupação. Após 35 dias do plantio realizou-se o $1^{\circ}$ - pastejo em $19 / 04$, o $2^{\circ}$ pastejo, o 3ํ e 4o ocorreram em 04/06; 25/07 e 04/09, após 46; 51 e 41 dias, respectivamente. Foram utilizadas 20 vacas da raça Holandês malhada de preto, com peso médio de $550 \mathrm{~kg}$ para o pastejo. Os animais foram utilizados apenas como ferramenta para rebaixar a pastagem, com média de taxa de lotação de 5,0 UA/ha. A entrada dos animais na área experimental foi determinada por meio da altura das plantas, estabelecendo-se como critério 1,0 a 1,2 m e a saída com altura de resíduo de $0,50 \mathrm{~m}$. A irrigação foi realizada a partir do $2^{\circ}$ pastejo $(04 / 06)$, utilizando-se lâmina d'água de $15 \mathrm{~mm}$ semanais, totalizando $60 \mathrm{~mm}$ de precipitação mensal.

Antes da desfolha pelos animais foram estudadas as variáveis massa de forragem inicial e proporção de folha (lâmina) e colmo (com bainha). As amostras foram obtidas através do corte rente ao solo das plantas e pesagem da forragem verde de duas amostras de $1 \mathrm{~m}^{2}$ tomadas por parcela e por ciclo de pastejo, sendo levada à estufa de renovação e circulação forçada de ar a $60^{\circ} \mathrm{C}$, para secagem até peso constante e posterior determinação da matéria seca. As análises de composição química da planta inteira, folha e colmo e a digestibilidade in vitro da matéria orgânica (DIVMO) da planta inteira foram realizados segundo Silva \& Queiroz (2002). A DIVMO foi feita segundo metodologia proposta por Tilley \& Terry (1963). O método utilizado foi o modificado, ou seja, realizado em duas etapas. Na primeira etapa o tempo de incubação foi de $48 \mathrm{~h}$ e na segunda $24 \mathrm{~h}$ e a quantidade de tubos analisados foram 216. Essa segunda etapa é recomendável para todas as forrageiras, pois é utilizada para desdobrar as proteínas dos microrganismos que se desenvolveram no processo fermentativo do substrato (SILVA \& QUEIROZ, 2002).

$\mathrm{O}$ delineamento experimental foi em blocos ao acaso (três blocos), em arranjo fatorial ( $3 \times 3$ ), sendo um dos fatores: três doses de adubação nitrogenada (100, 200 e $300 \mathrm{~kg}$ de N/ha na forma de uréia) e o outro fator: três doses de adubação potássica $\left(0,80\right.$ e $160 \mathrm{~kg}$ de $\mathrm{K}_{2} \mathrm{O} / \mathrm{ha}$ na forma de cloreto de potássio) e parcela subdividida no tempo (quatro ciclos de pastejos). Os dados experimentais foram submetidos à análise estatística pelo PROC GLM (SAS INSTITUTE, 2003). 


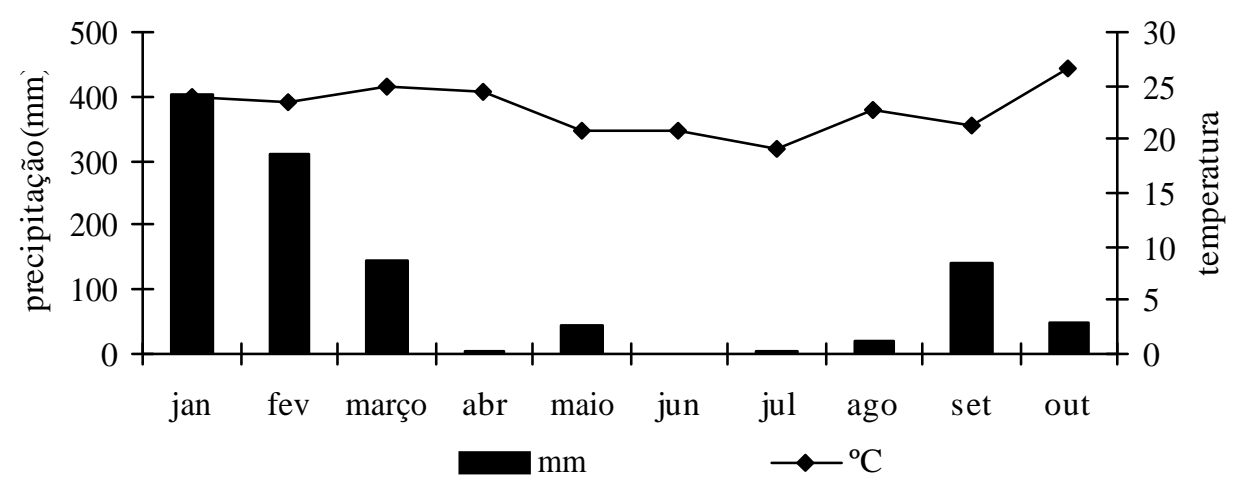

Figura 1 - Precipitação pluviométrica e temperatura durante o período experimental.

\section{RESULTADOS E DISCUSSÃO}

A adubação nitrogenada não influenciou a massa seca da forragem, e os valores para 100, 200 e $300 \mathrm{~kg}$ de N foram: 2713,7; 2680,2; 3009,7 kg/ha, respectivamente. No entanto, a porcentagem de colmos e folhas foi significativamente influenciada pelo nitrogênio, sendo que, para colmo, os valores foram: 49,9; 52,4; e 54,4\% (P=0,03) e para as folhas: 41,$2 ; 37,7 ; 35,7 \%(\mathrm{P}=0,005)$, respectivamente.

A adubação potássica não influenciou a massa seca, a porcentagem de colmos e folhas e seus valores para $0 ; 80$ e $160 \mathrm{~kg}$ de $\mathrm{K}_{2} \mathrm{O}$ foram: 2769,$1 ; 2778,9$ e $2855,6 \mathrm{~kg} / \mathrm{ha} ; 51,8$; 53,0 e $51,8 \%$ de colmo e 38,$9 ; 37,7$ e $37,9 \%$ de folha, respectivamente.

Guideli et al. (2000) realizaram um experimento com milheto em Jaboticabal-SP, com plantio na mesma época e observaram que a gramínea não respondeu às doses de nitrogênio aplicado, com produções de massa seca total de 2571; 2802; 2722 e 3103 para 0; 75; 150 e $225 \mathrm{~kg} / \mathrm{ha}$ de N. Segundo os autores, tal fato pode estar relacionado à deficiência hídrica ocorrida durante essa fase experimental.

Os ciclos de pastejo influenciaram significativamente a massa seca de forragem $(\mathrm{P}=0,0001)$ com valores de 2411,6 ; 2092,0; 2895,4 e 3805,9 kg/ha para 19/04; 04/06; 25/07 e 04/ 09 , respectivamente. Os colmos não foram influenciados pelos ciclos com valores de 53,62; 52,67; 49,26 e 53,36\%, no entanto, as folhas foram influenciadas $(\mathrm{P}=0,0001) \mathrm{com}$ valores de 46,37; 24,95; 41,61 e 39,91\%, respectivamente. Observa-se que o segundo ciclo de pastejo foi o mais prejudicado com o estresse hídrico e por isso sua produção de massa seca e de folhas foi menor.

$\mathrm{Na}$ análise da planta inteira, o nitrogênio não influenciou a porcentagem de matéria seca (MS), mas foi significativo para a proteína bruta (PB), o extrato etéreo (EE), a fibra em detergente neutro (FDN) a fibra em detergente ácido (FDA), a hemicelulose, a celulose e a lignina (Tabela 1). A adubação potássica aumentou significativamente a lignina. Porém, a interação não foi significativa $(\mathrm{P}>0,05)$ para as doses de nitrogênio e potássio $(\mathrm{N} \times \mathrm{K})$, para as variáveis estudadas.

Guideli et al. (2000) não observaram diferença significativa entre os parâmetros utilizados para avaliar a qualidade da forragem, com a adubação nitrogenada.

Valores semelhantes foram encontrados por Zago \& Ribas (1989), avaliando o valor nutritivo de forrageiras anuais sob corte, registraram valores de 17,4; 16,7 e 18,4\% para PB (proteína bruta) e 60,2; 59,2 e 72,1\%, para digestibilidade aparente da MS, respectivamente para híbrido de Sorgo-sudão cv. AG 2501C, milheto e aveia.

Fontaneli (1999) observou valores de PB $(14,4 \%)$ e de digestibilidade in vitro da matéria orgânica $(66,0 \%)$ ao avaliar diferentes cultivares de milheto e de híbrido de Sorgo-sudão.

Os ciclos de pastejos influenciaram significativamente a porcentagem das variáveis MS, PB, FDN, MM, lignina e digestibilidade, como observa-se na Tabela 2. O segundo ciclo foi o mais prejudicado em decorrência dos fatores climáticos citados anteriormente.

Restle et al. (2002) observaram valores de digestibilidade in vitro da matéria seca (DIVMS), para o híbrido de Sorgo-sudão cv. AG 2501C de 67,50 \%, diminuindo com o decorrer dos períodos. Cosér \& Maraschin (1981) avaliaram a DIVMO para o sorgo cv. Sordan NK sob pastejo contínuo e obtiveram o valor $69,9 \%$, na $1^{\text {a }}$ amostragem, com redução para $48,4 \%$ na última amostragem. Tal diminuição pode ser explicada pela redução ocorrida na proporção de folhas.

Segundo Soest (1994), a queda da digestibilidade nas forrageiras, com o avanço da maturidade, está associada ao aumento dos constituintes da parede celular, principalmente da lignina, além da diminuição na relação folha/colmo. 
Tabela 1 - Teores de matéria seca, proteína bruta, extrato etéreo, matéria mineral, FDN, FDA, hemicelulose, celulose e de lignina e digestibilidade in vitro da matéria orgânica (DIVMO), da planta inteira do híbrido de Sorgo-sudão cv. AG 2501C, submetido à adubação nitrogenada e potássica.

\begin{tabular}{|c|c|c|c|c|}
\hline & \multicolumn{3}{|c|}{ Níveis de nitrogênio } & \multirow[b]{2}{*}{$\mathrm{P}$} \\
\hline & 100 & 200 & 300 & \\
\hline Matéria seca (\%) & 17,4 & 16,3 & 17,3 & n.s \\
\hline Proteína bruta (\% da MS) & $15,1^{\mathrm{b}}$ & $16,4^{\mathrm{a}}$ & $15,7^{\mathrm{a}}$ & 0,04 \\
\hline Extrato etéreo (\% da MS) & $2,8^{\mathrm{a}}$ & $2,1^{\mathrm{b}}$ & $2,5^{\mathrm{a}}$ & $<0,001$ \\
\hline Matéria mineral (\% da MS) & 8,0 & 8,1 & 7,8 & n.s \\
\hline FDN (\% da MS) & $65,3^{\mathrm{a}}$ & $65,8^{\mathrm{a}}$ & $64,5^{\mathrm{b}}$ & 0,04 \\
\hline FDA (\% da MS) & $35,5^{\mathrm{c}}$ & $37,8^{\mathrm{b}}$ & $39,6^{\mathrm{a}}$ & $<0,001$ \\
\hline Hemicelulose (\% da MS) & $29,8^{\mathrm{a}}$ & $28,1^{\mathrm{b}}$ & $24,9^{\mathrm{c}}$ & $<0,001$ \\
\hline Celulose (\% da MS) & $30,6^{\mathrm{b}}$ & $31,9^{\mathrm{a}}$ & $32,7^{\mathrm{a}}$ & 0,007 \\
\hline Lignina (\% da MS) & $4,9^{\mathrm{c}}$ & $5,8^{\mathrm{b}}$ & $6,9^{\mathrm{a}}$ & $<0,001$ \\
\hline \multirow[t]{3}{*}{ DIVMO (\%) } & 71,8 & 73,9 & 71,6 & n.s \\
\hline & \multicolumn{3}{|c|}{ Níveis de potássio } & \\
\hline & 0 & 80 & 160 & $\mathrm{P}$ \\
\hline Matéria seca (\%) & 16,8 & 17,2 & 16,9 & n.s \\
\hline Proteína bruta (\% da MS) & 15,2 & 16,0 & 15,9 & n.s \\
\hline Extrato etéreo (\% da MS) & 2,6 & 2,3 & 2,5 & n.s \\
\hline Matéria mineral (\% da MS) & 7,9 & 7,8 & 8,1 & n.s \\
\hline FDN (\% da MS) & 65,3 & 65,3 & 65,1 & n.s \\
\hline FDA (\% da MS) & 37,1 & 37,6 & 38,2 & n.s \\
\hline Hemicelulose (\% da MS) & 28,2 & 27,7 & 26,7 & n.s \\
\hline Celulose (\% da MS) & 31,1 & 32,0 & 32,1 & n.s \\
\hline Lignina (\% da MS) & $5,9^{\mathrm{ab}}$ & $5,6^{\mathrm{b}}$ & $6,2^{\mathrm{a}}$ & 0,011 \\
\hline DIVMO (\%) & 72,7 & 71,9 & 72,7 & n.s \\
\hline
\end{tabular}

Letras minúsculas diferentes nas linhas diferem estatisticamente pelo teste de Tukey $(\mathrm{P}<0,05)$.

As análises de matéria seca, proteína bruta e matéria mineral da folha e do colmo, em separado, revelaram que houve efeito significativo apenas da adubação nitrogenada nos teores de proteína bruta da folha $(\mathrm{P}=0,02)$. Os demais parâmetros estudados não foram influenciados $(\mathrm{P}>0,05)$ pela adubação nitrogenada ou potássica (Tabela 3 ).

Os teores de PB observados nas folhas foram sempre maiores que os do colmo com bainha. O mesmo foi relatado por Oliveira et al. (2000), em experimento com o capim-Tifton 85 , no qual os teores de PB observados na fração folha foram maiores que os dos colmos, para todas as idades estudadas. Desse modo, destaca-se a importância das folhas no valor nutritivo e consumo das forrageiras, rapidamente digeridas e degradadas no rúmen, comparadas aos colmos.
Além disso, em condições de pastejo, o animal é capaz de selecionar folhas e colmos menos maduros, destacando-se, então, a relação folha/colmo como componente importante no manejo de plantas forrageiras, aliado ao conhecimento da composição bromatológica do pasto.

Os ciclos de pastejos influenciaram $(\mathrm{P}<0,001)$, a matéria seca, a proteína bruta e a matéria mineral das folhas e dos colmos, respectivamente (Tabela 4).

Observa-se menor teor de PB nos colmos do $2^{\circ}$ ciclo. Com o uso da irrigação no $3^{\circ}$ e o $4^{\circ}$ ciclo a qualidade da forragem se manteve. Provavelmente, nesse período, em que a distribuição de chuvas foi desuniforme, a qualidade dos colmos foi influenciada pelos fatores climáticos. 
Tabela 2 - Teores de matéria seca, proteína bruta, extrato etéreo, matéria mineral, FDN, FDA, hemicelulose, celulose e de lignina e digestibilidade in vitro da matéria orgânica (DIVMO), da planta inteira do híbrido de Sorgo-sudão cv. AG 2501C, nos ciclos de pastejo.

\begin{tabular}{|c|c|c|c|c|c|}
\hline & \multicolumn{5}{|c|}{ Ciclos de pastejo } \\
\hline & $19 / 04$ & $04 / 06$ & $25 / 07$ & 04/09 & $\mathrm{P}$ \\
\hline Matéria seca (\%) & $13,2^{\mathrm{c}}$ & $18,9^{\mathrm{a}}$ & $16,4^{\mathrm{b}}$ & $19,5^{\mathrm{a}}$ & $<0,001$ \\
\hline Proteína bruta (\% da MS) & $15,0^{\mathrm{c}}$ & $13,8^{\mathrm{d}}$ & $17,2^{\mathrm{a}}$ & $16,1^{b}$ & $<0,001$ \\
\hline Extrato etéreo (\% da MS) & 2,4 & 2,4 & 2,7 & 2,4 & n.s \\
\hline Matéria mineral (\% da MS) & $8,7^{\mathrm{a}}$ & $7,2^{\mathrm{d}}$ & $8,2^{\mathrm{bc}}$ & $7,8^{\mathrm{c}}$ & $<0,001$ \\
\hline FDN (\% da MS) & $65,0^{\mathrm{ab}}$ & $65,7^{\mathrm{ab}}$ & $64,1^{\mathrm{b}}$ & $66,0^{\mathrm{a}}$ & 0,02 \\
\hline FDA (\% da MS) & 38,2 & 37,7 & 37,1 & 37,5 & n.s \\
\hline Hemicelulose (\% da MS) & 26,8 & 28,02 & 27,03 & 28,5 & n.s \\
\hline Celulose (\% da MS) & 32,7 & 31,3 & 31,3 & 31,5 & n.s \\
\hline Lignina (\% da MS) & $5,4^{\mathrm{b}}$ & $6,3^{\mathrm{a}}$ & $5,8^{\mathrm{ab}}$ & $6,0^{\mathrm{ab}}$ & 0,003 \\
\hline DIVMO $(\%)$ & $76,1^{\mathrm{a}}$ & $67,5^{b}$ & $73,5^{\mathrm{a}}$ & $72,7^{\mathrm{a}}$ & $<0,001$ \\
\hline
\end{tabular}

Letras minúsculas diferentes nas linhas diferem estatisticamente pelo teste de Tukey $(\mathrm{P}<0,05)$.

Tabela 3 - Teores de matéria seca, proteína bruta e matéria mineral das folhas e dos colmos, do híbrido de Sorgo-sudão cv. AG 2501C, submetido à adubação nitrogenada e potássica.

\begin{tabular}{|c|c|c|c|c|}
\hline \multirow[b]{2}{*}{ FOLHA } & \multicolumn{4}{|c|}{ Níveis de nitrogênio } \\
\hline & 100 & 200 & 300 & $\mathrm{P}$ \\
\hline Matéria seca (\%) & 21,8 & 22,2 & 22,1 & n.s \\
\hline Proteína bruta (\% da MS) & $19,5^{b}$ & $19,8^{\mathrm{ab}}$ & $20,4^{\mathrm{a}}$ & 0,02 \\
\hline \multirow[t]{3}{*}{ Matéria mineral (\% da MS) } & 7,4 & 7,3 & 7,5 & n.s \\
\hline & \multicolumn{4}{|c|}{ Níveis de potássio } \\
\hline & 0 & 80 & 160 & $\mathrm{P}$ \\
\hline Matéria seca (\%) & 22,2 & 21,9 & 22,0 & n.s \\
\hline Proteína bruta (\% da MS) & 19,6 & 19,8 & 20,3 & n.s \\
\hline \multirow[t]{2}{*}{ Matéria mineral (\% da MS) } & 7,5 & 7,3 & 7,5 & n.s \\
\hline & \multicolumn{4}{|c|}{ Níveis de nitrogênio } \\
\hline COLMO & 100 & 200 & 300 & $\mathrm{P}$ \\
\hline Matéria seca (\%) & 14,0 & 14,1 & 14,6 & n.s \\
\hline Proteína bruta (\% da MS) & 10,3 & 10,1 & 10,5 & n.s \\
\hline \multirow[t]{3}{*}{ Matéria mineral (\% da MS) } & 9,5 & 9,1 & 8,9 & n.s \\
\hline & \multicolumn{4}{|c|}{ Níveis de potássio } \\
\hline & 0 & 80 & 160 & $\mathrm{P}$ \\
\hline Matéria seca (\%) & 14,4 & 14,1 & 14,2 & n.s \\
\hline Proteína bruta (\% da MS) & 10,0 & 10,3 & 10,6 & n.s \\
\hline Matéria mineral (\% da MS) & 8,9 & 9,2 & 9,3 & n.s \\
\hline
\end{tabular}

Letras minúsculas diferentes nas linhas diferem estatisticamente pelo teste de Tukey $(\mathrm{P}<0,05)$. 
Tabela 4 - Teores de matéria seca, proteína bruta e matéria mineral das folhas e dos colmos, do híbrido de Sorgo-sudão cv. AG 2501C, nos ciclos de pastejo.

\begin{tabular}{|c|c|c|c|c|c|}
\hline \multirow[b]{2}{*}{ FOLHA } & \multicolumn{5}{|c|}{ Ciclos de pastejo } \\
\hline & $19 / 04$ & $04 / 06$ & $25 / 07$ & 04/09 & $\mathrm{P}$ \\
\hline Matéria seca \% & $18,8^{\mathrm{d}}$ & $25,5^{\mathrm{a}}$ & $21,0^{\mathrm{c}}$ & $22,7^{b}$ & $<0,001$ \\
\hline Proteína bruta (\% da MS) & $18,8^{\mathrm{c}}$ & $19,7^{\mathrm{b}}$ & $21,0^{\mathrm{a}}$ & $20,1^{\mathrm{ab}}$ & $<0,001$ \\
\hline Matéria mineral (\% da MS) & $7,5^{\mathrm{a}}$ & $7,0^{\mathrm{b}}$ & $7,8^{\mathrm{a}}$ & $7,4^{\mathrm{ab}}$ & $<0,001$ \\
\hline \multicolumn{6}{|l|}{ COLMO } \\
\hline Matéria seca \% & $10,2^{\mathrm{c}}$ & $15,5^{\mathrm{a}}$ & $14,6^{\mathrm{ab}}$ & $16,7^{\mathrm{a}}$ & $<0,001$ \\
\hline Proteína bruta (\% da MS) & $10,7^{\mathrm{b}}$ & $8,4^{\mathrm{c}}$ & $11,6^{\mathrm{a}}$ & $10,5^{\mathrm{b}}$ & $<0,001$ \\
\hline Matéria mineral (\% da MS) & $10,0^{\mathrm{a}}$ & $7,5^{\mathrm{b}}$ & $9,9^{\mathrm{a}}$ & $9,2^{\mathrm{a}}$ & $<0,001$ \\
\hline
\end{tabular}

Letras minúsculas diferentes nas linhas diferem estatisticamente pelo teste de Tukey $(\mathrm{P}<0,05)$.

\section{CONCLUSÕES}

A composição química e a digestibilidade in vitro da matéria orgânica do híbrido de Sorgo-sudão cv. AG 2501C não aumentaram com as adubações nitrogenadas e potássicas, em razão da alta fertilidade do solo e da baixa precipitação pluviométrica, em função do solo e da época do experimento, por isso, a adubação nitrogenada de 100 $\mathrm{kg} / \mathrm{ha}$ é suficiente nessas condições.

\section{REFERÊNCIAS BIBLIOGRÁFICAS}

BROYLES, K. R.; FRIBOURG, H. A. Nitrogen fertilizantion and cutting management of sudangrass and millets. Agronomy Journal, Madison, v. 51, n. 5, p. 277-279, 1959.

CÓSER, C. A.; MARASCHIN, E. G. Produção e qualidade da forragem de milheto comum e sorgo cv. Sordan NK sob pastejo. Pesquisa Agropecuária Brasileira, Brasília, v. 16, n. 3, p. 397-403, 1981.

EMPRESA BRASILEIRA DE PESQUISA AGROPECUÁRIA. Centro Nacional de Pesquisa de solos. Sistema brasileiro de classificação de solos. Brasília, DF, 1999. 412 p.

FERREIRA, J. J.; CARNEIRO, J. C.; RODRIGUES, J. A.; BARROS NETO, G. Produção e composição bromatológica do capim Sudão e de seus híbridos (BRS 800 e AG 2501 C) com 42 e 56 dias. In: REUNIÃO ANUAL DA SOCIEDADE BRASILEIRA DE ZOOTECNIA, 37., 2000, Viçosa. Anais... Viçosa: SBZ, 2000. CD-ROM.

FONTANELI, S. R. Forage systems for year-round grazing by lactating dairy cows. $217 \mathrm{f}$. Thesis (Ph.D.) - University of Florida, Gainesville, 1999.
JUNG, G. A.; LILLY, B.; SHIH, S. C.; REID, R. L. Effect of growth stage and level of nitrogen fertilizer upon yield of dry matter and protein, aminoacid composition and prussic acid potential. Agronomy Journal, Madison, v. 56, n. 6, p. 533-537, 1964.

GUIDELI, C.; FAVORETTO, V.; MALHEIROS, E. B. Produção e qualidade do Milheto semeado em duas épocas e adubado com nitrogênio. Pesquisa Agropecuária Brasileira, Brasília, v. 35, n. 10, out. 2000.

HART, R. H.; BURTON, G. W. Effect of row spacing, seeding rate and nitrogen fertilization on forage yield and quality of Gahil-1 Pearl millet. Agronomy Journal, Madison, v. 57, n. 4 , p. $376-378,1965$.

MEDEIROS, R. B.; SAIBRO, J. C.; BARRETO, I. L. Efeito do nitrogênio e da população de plantas no rendimento e qualidade do sorgo sordan (Sorghum bicolor (L.) Moench $x$ Sorghum sudanense (Piper) Stapf). Revista da Sociedade Brasileira de Zootecnia, Viçosa, v. 8, n. 1, p. 75-87, 1979.

OLIVEIRA, M. A.; PEREIRA, O. G.; GARCIA, R.; OBEID, J. A.; CECON, P. R.; MORAES, S. A.; SILVEIRA, P. R. Rendimento e valor nutritivo do Capim-Tifton 85 (Cynodon spp.) em diferentes idades de rebrota. Revista Brasileira de Zootecnia, Viçosa, v. 29, n. 6, p. 1949-1960, 2000.

RESTLE, J.; ROSO, C.; AITA, V.; NORNBERG, J. L.; BRONDANI, I. L.; CERDÓTES, L.; CARRILHO, C. O. Produção animal em pastagem com gramíneas de estação quente. Revista Brasileira de Zootecnia, Viçosa, v. 31, n. 3, p. 1491-1500, 2002. 
SAS INSTITUTE. User's guide: statistics. Cary, 2003. $965 \mathrm{p}$.

SILVA, J. D.; QUEIROZ, A. C. Análise de alimentos: métodos químicos e biológicos. 3. ed. Viçosa: UFV, 2002. $235 \mathrm{p}$.

SOEST, P. J. van. Nutritional ecology of the ruminant. New York: Cornell, 1994.
TILLEY, J. M. A.; TERRY, R. A. A two-stage technique for the in vitro digestion of forage crops. Journal of British Grassland Society, Hurley, v. 18, n. 2, p. 104-111, 1963.

ZAGO, C. P.; RIBAS, P. M. AG 2501-C: novo híbrido forrageiro de sorgo x capim Sudão, para corte e pastejo. In: REUNIÃO ANUAL DA SOCIEDADE BRASILEIRA DE ZOOTECNIA, 26., 1989, Porto Alegre, RS. Anais... Porto Alegre: SBZ, 1989. p. 142. 